\title{
Host Sex Steroids Interact With Virus Infection: New Insights Into Sex Disparity in Infectious Diseases
}

\author{
Jinfeng Wu, Lei Zhang and Xing Wang* \\ Key Laboratory of Gastrointestinal Cancer (Ministry of Education), School of Basic Medical Sciences, Fujian Medical \\ University, Fuzhou, China
}

Sex hormones are steroid hormones synthesized from the gonads of animals and tissues such as the placenta and adrenocortical reticular zone. The physiological functions of sex hormones are complex. Sex hormones are not only pathologically correlated with many diseases of the reproductive system, but are etiological factors in some viral infectious diseases, including disease caused by infections of coronaviruses, herpesviruses, hepatitis viruses, and other kinds of human viruses, which either exhibit a male propensity in clinical practice, or crosstalk with androgen receptor (AR)-related pathways in viral pathogenesis. Due to the global pandemic of coronavirus disease

OPEN ACCESS

Edited by: Xing-Yi Ge,

Hunan University, China

Reviewed by: Alexander Freiberg, University of Texas Medical Branch at Galveston, United States Jungang Chen, University of Arkansas for Medical

Sciences, United States

*Correspondence: Xing Wang

xwang623@fjmu.edu.cn

Specialty section:

This article was submitted to Virology,

a section of the journal

Frontiers in Microbiology

Received: 26 July 2021 Accepted: 27 September 2021 Published: 04 November 2021

Citation:

Wu JF, Zhang $L$ and Wang $X$ (2021) Host Sex Steroids Interact With Virus Infection: New Insights Into

Sex Disparity in Infectious Diseases.

Front. Microbiol. 12:747347.

doi: 10.3389/fmicb.2021.747347
2019 (COVID-19), the role of androgen/AR in viral infectious disease is highlighted again, majorly representing by the recent advances of AR-responsive gene of transmembrane protease/serine subfamily member 2 (TMPRSS2), which proteolytically activates the receptor-mediated virus entry by many coronaviruses and influenza virus, along with the role of androgen-mediated signaling for the transcription of hepatitis B virus (HBV), and the role of sex hormone responsive genes during Zika virus (ZIKV) pathogenesis, et al. Collectively, we propose to provide a comprehensive overview of the role of male sex hormones during multiple phases in the life cycle of different human viruses, which may be partly responsible for the sex-specific prevalence, severity and mortality of some diseases, therefore, may provide clues to develop more efficient prevention and treatment strategies for high-risk populations.

Keywords: human viruses, virus infection, male predominance, androgen receptor, transmembrane protease/serine subfamily member 2

\section{INTRODUCTION}

The ongoing pandemic of COVID-19, caused by severe acute respiratory syndrome coronavirus 2 (SARS-CoV-2), highlights those viral infectious diseases still present a serious threat to human health (Guan et al., 2020; Rozenberg et al., 2020). This is also evident from the regional outbreaks of influenza (Iuliano et al., 2018), viral hepatitis (Lee and Banini, 2019; Megahed et al., 2020), Ebola virus disease (EVD) (WHO, 2016), and the Zika epidemic (Duffy et al., 2009; Musso et al., 2014), all of which exhibit a male propensity for virus infection and pathogenesis that is mediated by different mechanisms.

Male bias in COVID-19 mortality is observed in nearly all countries with available sexdisaggregated data, and the risk of death in males is 1.7 times higher than in females 
(Scully et al., 2020). This disparity was first reported in China, where, the death rate among men was $2.8 \%$ vs. $1.7 \%$ in women (Gemmati et al., 2020). Regarding the infection rate, the ratio in males to females was 3:1 in Italy (Gebhard et al., 2020). Notably, there are several other viruses, including Kaposi's sarcoma-associated herpesvirus (KSHV), HBV, influenza virus, and Respiratory syncytial virus (RSV) which predominantly affect males (Tsay et al., 2009; Lorenzo et al., 2011; Jones et al., 2019; Orimadegun et al., 2020). KSHV, HBV, and hepatitis $\mathrm{C}$ virus (HCV) are three types of human oncoviruses, which are defined as sex hormone responsive (Bosch et al., 2004; Jemal et al., 2011; Bradley et al., 2020). It was reported that men are more susceptible to seasonal influenza virus, and that the clinical outcomes are more severe (Wong et al., 2019). Besides, invasion or damage of the male reproductive system are reported outcomes of viral infection with SARS-CoV-2, Ebola virus (EBOV), and ZIKV (Counotte et al., 2018; Den Boon et al., 2019; Vishvkarma and Rajender, 2020). Taken together, these data suggest the significant implications of sex hormones in the gender differences observed in virus-associated susceptibility, prevention, clinical manifestations, treatment, prognosis, and pathogenesis (Baggio et al., 2013).

Androgen receptor is a ligand-dependent nuclear transcription factor (Dai et al., 2017). It mainly works in combination with natural agonists such as testosterone and dihydrotestosterone (DHT). At the absence of the ligand, AR complex with heat shock proteins and immunophilin, anchoring to cyto-skeletal elements, and residing primarily in the cytoplasm (Smith and Toft, 2008). However, upon the binding of ligand, the homodimer of ligand-AR translocates from cytoplasm to nucleus and binds to the androgen response elements (AREs) of target genes, thus regulating the downstream transcription cascades (Claessens et al., 2001; Dai et al., 2017). TMPRSS2, a well-known AR-responsive gene, emerged as hot topics in COVID-19 by processing a universal proteolytical activating effect to coronavirus family and influenza virus (Kawase et al., 2012; Böttcher-Friebertshäuser et al., 2014; Yamamoto et al., 2016; Shen et al., 2017; McKee et al., 2020), thus emphasize the requirement to fully elucidate the molecular mechanisms which underling the sex disparity in several viral infectious diseases.

Most studies to date have investigated this discrepancy in terms of gender-specific immune responses, and the results have shown that females have a greater ability to elicit immune responses against infection (Moulton, 2018; Ortona et al., 2019). Some hypotheses, which are mainly discussed in the review, suggest a direct effect by male sex hormones on pathogen infection. TMPRSS2, which is expressed in an androgendependent manner, is utilized by SARS-CoV-2 for the priming of viral spike $(S)$ protein, which is essential for viral entry into primary target cells and for viral spread in the infected host (Mjaess et al., 2020). Similarly, TMPRSS2 acts as the major hemagglutinin (HA)-activating protease of influenza A virus (IAV) in human airway cells and of influenza B virus (IBV) in type II pneumocytes (Limburg et al., 2019). To the early-stage infection of other viruses, AR is involved in the coordinated activation of Src/RSK1/EphA2 Ser897 signaling, which promotes primary infection by KSHV (Wang et al., 2017). On the contrary,
$17 \beta$-estradiol (E2) can inhibit HCV spread and/or entry by activating G-protein-coupled estrogen receptor, GPR30, increasing matrix metalloproteinase 9 (MMP-9) activation and exporting to the extracellular space leading to cleavage of occludin in Domain D (Ulitzky et al., 2016). The welldocumented role of HBV in hepatocellular carcinoma (HCC) indicates that a virus-host feedback loop between the $\mathrm{X}$ gene of $\mathrm{HBV}$ and AR is established in HBV-infected male hepatocytes (Zhu et al., 2011). Similarly, HCV core protein mediated the feedback loop between AR and JAK/STAT signaling pathway also plays a vital role in HCV infection (Kanda et al., 2008).

Hence, this review aimed to further analyze the literature concerning (i) the implication of the androgen/AR axis and its downstream signaling in primary virus infection, and (ii) other mechanisms mediated by sex steroids or associated molecules in the regulation of virus replication or viral pathogenesis. This review may provide strategies for endocrine-based interventions and personalized treatment for high-risk groups.

\section{CORONAVIRUSES}

Transmembrane protease/serine subfamily member 2 is an androgen-regulated gene encoding a transmembrane serine protease (Figure 1A), which is located on human chromosome 21q22.3, and is approximately $66 \mathrm{~kb}$ in length (Shen et al., 2017). The full-length TMPRSS2 cDNA encodes a polypeptide of 492 amino acids, with a domain structure comprising a type II transmembrane domain, a receptor class A domain, a scavenger receptor cysteine-rich domain and a C-terminal ectodomain encompassing a large serine protease subunit (Figure 1B; Bottcher-Friebertshauser et al., 2010). It is well established that TMPRSS2 is highly expressed in prostate epithelial cells, and the TMPRSS2-ERG [erythroblast transformation-specific transcription factor (ETS) -related gene, ERG] fusion gene is frequently expressed in benign prostatic hyperplasia and primary prostate cancer tissues (Perner et al., 2007; FitzGerald et al., 2008; Park et al., 2014). In recent years, TMPRSS2 was confirmed to play a critical role in catalyzing virus-cell membrane fusion during SARS-CoV infection by proteolytically cleaving the $S$ protein and activating its conformational flexibility (Heurich et al., 2014; Zmora et al., 2015). It is notable that this process is hijacked by a variety of human viruses, including middle east respiratory syndrome coronavirus (MERS-CoV) (Shirato et al., 2013), IAV (Tarnow et al., 2014; Cheng et al., 2015), and HCV (Esumi et al., 2015). Therefore, TMPRSS2 has emerged as a promising antiviral candidate in many types of infectious diseases (Kawase et al., 2012; Yamamoto et al., 2016; McKee et al., 2020).

Like other class I viral fusion proteins, the human coronavirus spike (S) proteins require proteolytic priming to be activated (Bertram et al., 2012; Zhou et al., 2015). Priming of coronavirus $S$ by host cell proteases is essential for viral entry into cells (Figure 1). The S proteins include cell receptor-binding domains (RBDs) and virus-cell membrane fusion domains (Kirchdoerfer et al., 2016). The S1/S2 cleavage site of SARS-CoV-2 S harbors several arginine residues (multibasic residues), which indicate its high cleavability (Figure 1C). Hoffmann et al. (2020) showed 


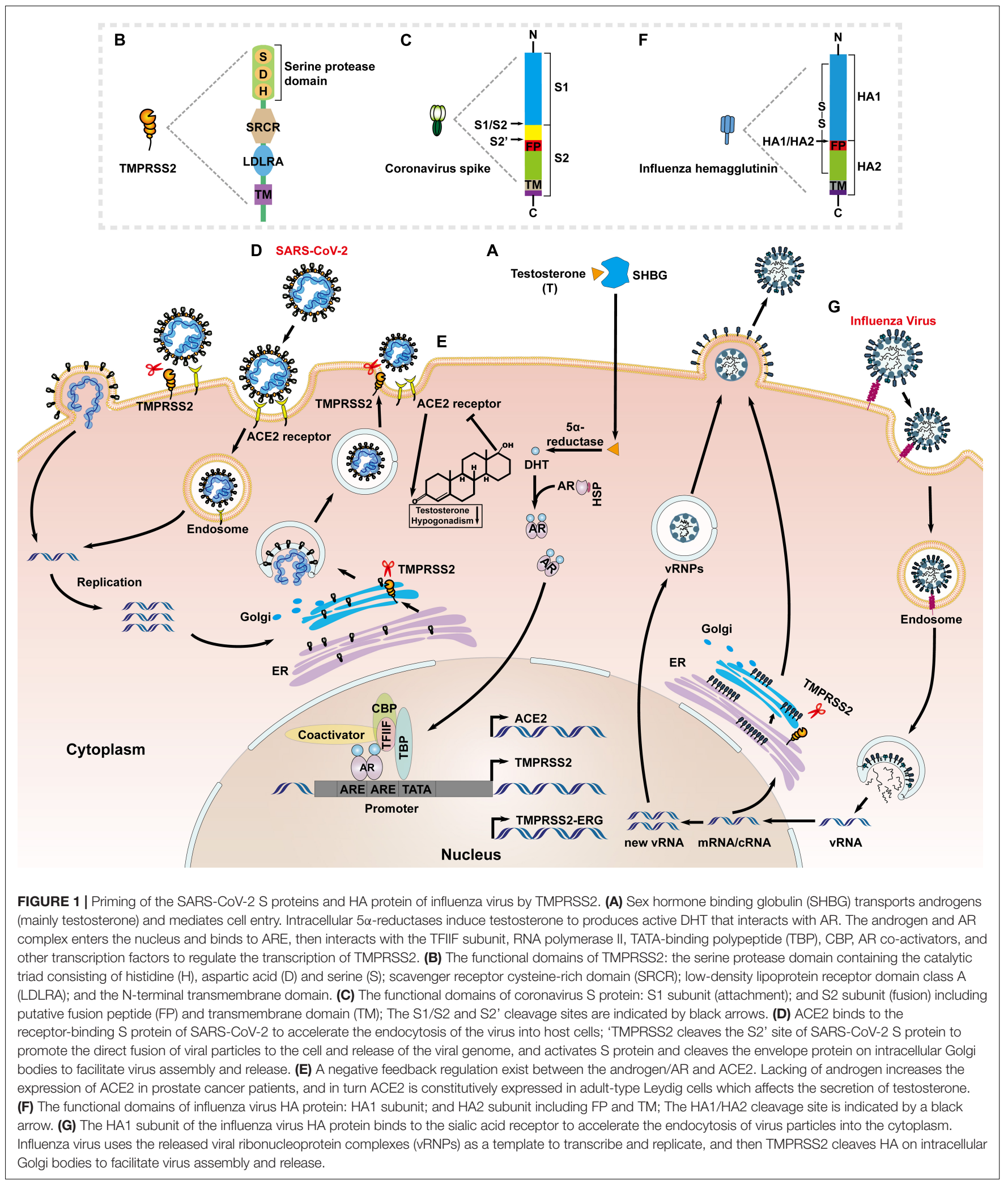

that SARS-CoV-2 depends on furin-mediated precleavage of its $\mathrm{S}$ protein at the $\mathrm{S} 1 / \mathrm{S} 2$ site for subsequent $\mathrm{S}$ protein activation by TMPRSS2 in lung cells (Figure 1D; Bestle et al., 2020;
Hoffmann et al., 2020). Furin cleaves the R-R-A-R685 $\downarrow$ site in the S1/S2 domain of S protein, whereas, TMPRSS2 cleavage occurs at KR815 $\downarrow$ at the S2' site (Coutard et al., 2020; Walls et al., 2020). 
For MERS-CoV, TMPRSS2 mediated precleavage at the S1/S2 motif (RSVR751), but this was not essential for subsequent virus activation. By contrast, the S2 site (RSAR) was required for efficient entry and the integrity of one of the two arginines was sufficient for cleavage, usually most of which are cleaved by TMPRSS2 or cathepsin L (Kleine-Weber et al., 2018). In the case of SARS virus, TMPRSS2 cleaved and activated the $S$ protein at separate sites, i.e., R667 and R797 (Reinke et al., 2017).

Transmembrane protease/serine subfamily member 2 has been widely studied in the context of prostate cancer, where, it is highly expressed, and TMPRSS2 expression is increased in response to androgens through direct transcriptional regulation by the AR (Lin et al., 1999; Lucas et al., 2014). A 15-bp sequence of the androgen response element is located at position $\sim 148$ from the putative transcriptional start site of TMPRSS2 (Figure 1A; Lin et al., 1999). This feature has been hypothesized to contribute to the high frequency of genomic rearrangements involving the TMPRSS2 promoter and ERG, which places this oncogene under AR control (Haffner et al., 2010). Taken together, inhibition of AR activity and downregulation of TMPRSS2 could be targeted to prevent SARS-CoV-2 infection (Stopsack et al., 2020). This hypothesis was partly supported by a retrospective study in Italy that found that prostate cancer patients receiving androgen deprivation therapy (ADT) were less susceptible to SARS-CoV-2 infection (Montopoli et al., 2020). The reasons for these gender disparities are still under investigation. Recent studies reported that the active genetic variant of AR, with a long CAG repeat, is associated with more severe COVID-19 disease (McCoy et al., 2021).

The cellular receptor of SARS-CoV-2, angiotensin-converting enzyme 2 (ACE2), was identified as another AR-regulated target (Majdic, 2020; Qiao et al., 2020; Figure 1A). Different from that of male sex hormones-activating TMPRSS2, a negative feedback regulation exists between the androgen/AR and ACE2 (Figure 1E). That is, ADT might increase ACE2 expression in patients of prostate cancer, which might be beneficial when SARS-CoV-2 competes with angiotensin II for binding sites (Cattrini et al., 2020). On the other hand, ACE2 is constitutively expressed in adult-type Leydig cells which affect the secretion of testosterone, and the mechanism may account for the testosterone deficiency in men infected with COVID-19 (Hackett and Kirby, 2020; Hussain et al., 2020; Giagulli et al., 2021). Transcriptional repression of the AR enhanceosome with AR or the bromodomain and extraterminal domain (BET) antagonists led to decreased expression of both TMPRSS2 and ACE2 in subsets of lung epithelial cells, and inhibited SARS-CoV-2 infection in vitro (Qiao et al., 2020). A few AR-binding motifs were also identified within ACE2 regulatory regions (Ragia and Manolopoulos, 2020), but it is still not known whether these elements actually cause the ACE2 promoter to exhibit an androgen-dependent response.

The full array of mechanisms responsible for the gender disparities observed in COVID-19 outcomes is likely to be multifactorial. The androgen/AR axis exhibits a multidimensional response to SARS-CoV-2 infection, from active genetic variants to transcriptional regulation of host entry factors by TMPRSS2 and ACE2.

\section{HERPESVIRUSES}

In contrast to the genomic regulation of $\mathrm{AR}$ to the key target genes, such as TMPRSS2 and ACE2, that promote coronavirus and influenza virus infection (Lin et al., 1999; Shen et al., 2017), membrane-localized AR has been shown for the first time to be associated with KSHV entry and endocytosis (Wang et al., 2017). Cell entry by KSHV is a multistep process involving viral envelope glycoproteins as well as several cellular attachment and entry factors (Chandran, 2010; Chakraborty et al., 2012). One such factor is ephrin receptor A2 (EphA2), which is localized to the cell membrane subdomains/lipid rafts, and Wang et al. (2017) demonstrated that AR act as a host factor to facilitate KSHV entry by mediating Src/RSK1/EphA2 Ser897 signaling cascades (Figure 2A). KSHV envelope glycoproteins $\mathrm{H}$ and $\mathrm{L}$ bind to EphA2 and trigger the phosphorylation of EphA2, thereby promoting endocytosis of $\mathrm{KSHV}$, which involves the signaling cascades mentioned above (Akula et al., 2003; Raghu et al., 2009). The specific mechanism involves the AR-mediated recruitment of Src, leading to the activation of p90 ribosomal S6 kinase 1 (RSK1), which in turn, leads to Ser897 phosphorylation of EphA2 (Figure 2A). From these results, it can be concluded that the gender difference in KSHV infection may be related to the cascade of androgens that promote KSHV infection of endothelial cells and epithelial cells. This may also imply a new mechanism affected by gender differences in the pathogenesis of Kaposi's sarcoma.

Zhang et al. (2018) recently reported that EphA2 is also a key receptor for Epstein-Barr virus (EBV) to infect epithelial cell. As a member of gamma-herpesvirus of human herpes virus type IV, the infection of EBV is also associated with sex hormones (Sasaki et al., 2020). Persistent EBV reactivation induces host B cells to differentiate into plasma cells and produce various isotypes of $\mathrm{Ig}$, relating to autoimmune diseases (Hara et al., 2018), such as Graves' disease (Hara et al., 2019) and Multiple sclerosis (MS) (Al-Temaimi et al., 2015), which occur predominantly in women. However, the progression of MS was more severe in male patients $(55.1 \%)$ than in females $(34.8 \%)$ (Al-Temaimi et al., 2015). In addition, studies have shown that the use of progesterone analog may decrease the DNA titer of EBV in plasma of cachectic patients with recurrent/metastatic nasopharyngeal carcinoma (NPC) (Hung et al., 2017). However, the underlying mechanism by which AR-pathways may involve in the process remains elusive and should be very interesting in the future work.

\section{HUMAN HEPATITIS VIRUSES}

Virus-induced HCC is present worldwide, representing 60$80 \%$ of all liver cancer cases and the risk factors of viral infection with $\mathrm{HBV}$ is $54 \%$ of all HCCs, and/or HCV is $31 \%$ of all HCCs (El-Serag, 2012; Yang et al., 2019). Moreover, HBV and HCV infection showed explicit genderrelated differences (Tsay et al., 2009; Bradley et al., 2020). However, the mechanisms of sex disparities in HBV and HCV infection are considerable differences. 


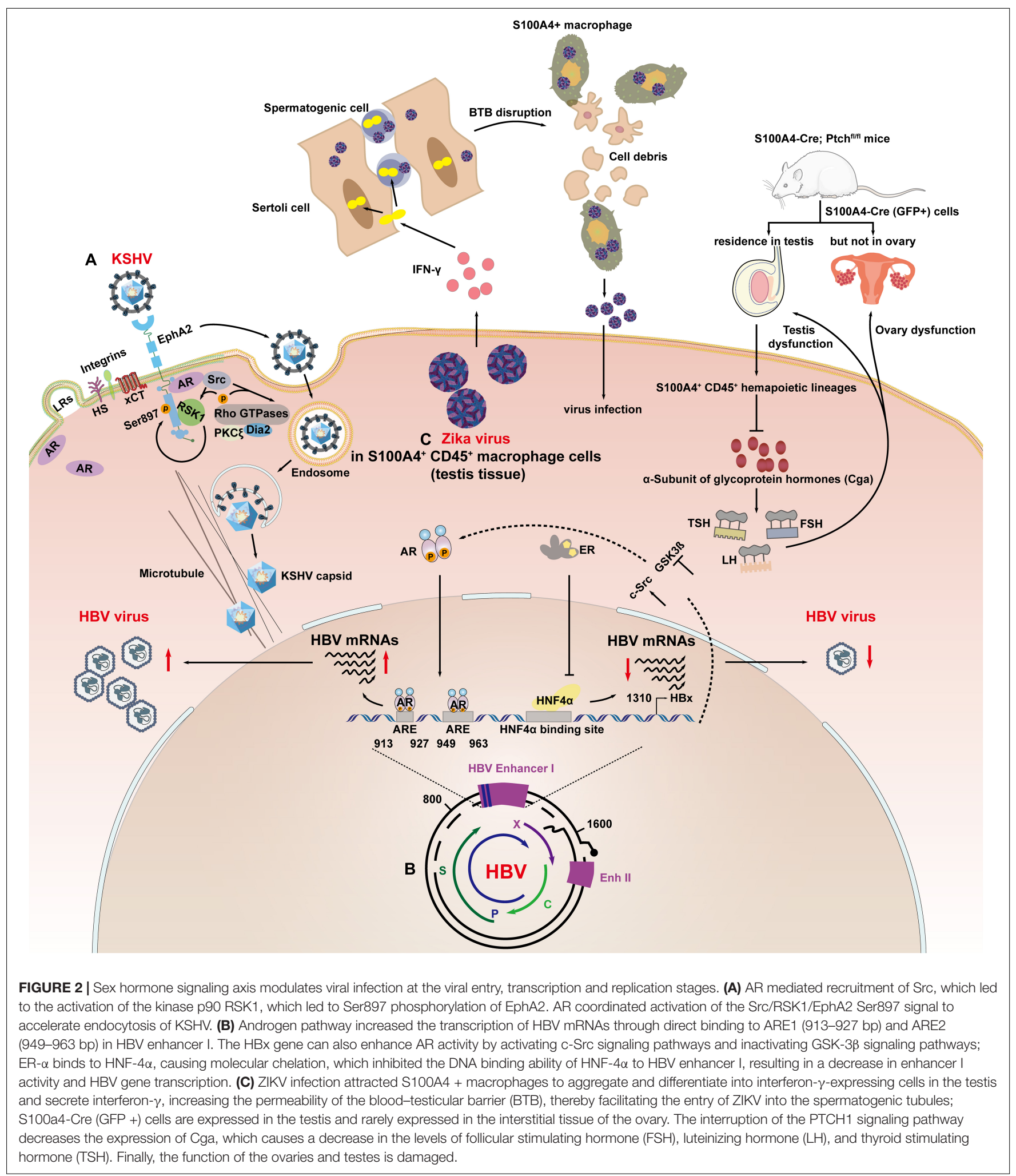

Researchers reported that the rate of spontaneous clearance of $\mathrm{HBV} / \mathrm{HCV}$ was higher among $\mathrm{HBV} / \mathrm{HCV}$-infected females when compared with male patients (Bakr et al., 2006; Wang et al., 2007), and sustained virologic response (SVR) was more prominent among male patients (Akuta et al., 2007; Iyer et al., 2017). Differences in immune capacity between men and women may be part of reasons to this bias, and it was reported that number of monocytes, macrophages and dendritic cells, which participated 
in preventing human from virus infection were higher in females (Klein, 2012). Besides, women usually produce more effective immune responses than men after virus infection (Ruggieri et al., 2016). On the other hand, gender bias in virus entry, transcription and replication can also contribute to this bias.

Sodium taurocholate co-transporting polypeptide (NTCP) has been supposed to play a key role for HBV entering (Yan et al., 2012), and it was reported that NTCP mRNA and protein expression were higher in male than female in rat hepatic sinusoid (Simon et al., 2004). Similarly, the entry of HCV for human liver cells also display gender differences. Scavenger receptors, which are critical for HCV entry were reported could be up-regulated by testosterone whiling be down-regulated by estrogen (Langer et al., 2002; Scarselli et al., 2002; Stangl et al., 2002; Evans et al., 2007; Meng et al., 2011). In addition, E2 was also reported to inhibit $\mathrm{HCV}$ entry through down-regulation of occludin (OCLN), which is also critical for viral infection (Ulitzky et al., 2016), it can activate GPR30, increase MMP9 activation and export to the extracellular space leading to cleavage of occludin in Domain $\mathrm{D}$, disrupting occludin-occludin and occludin-claudin-1 interaction.

Sex hormone pathways classically modulate HBV infection by activating their cognitive nuclear receptors, which act as transcriptional regulators, controlling the expression of $\mathrm{HBV}$ genes (Figure 2B; Wang et al., 2009, 2012). Wang et al. (2009) reported that the androgen pathway can increase the transcription of HBV mRNAs through direct binding to ARE1 (913-927 bp) and ARE2 (949-963 bp) in HBV enhancer I (Ruggieri et al., 2018). In turns, studies reported that HBx could promote AR transcriptional activity through glycogen synthase kinase-3 $\beta$ (GSK-3 $\beta$ ) and c-Src kinase pathway (Chiu et al., 2007; Yang et al., 2009). This forms a positive loop which promotes the progression of HBV infection seriously in males. On the contrary, Wang et al., also concluded that estrogen receptor- $\alpha$ (ER- $\alpha$ ) could reduce transcription of the $\mathrm{HBV}$ gene by suppressing HBV enhancer I activity. The hinge region and the boundary region between the DNA binding domain (DBD) and the hinge (amino acids 252-263) of ER- $\alpha$ bind to hepatocyte nuclear factor4 alpha (HNF-4 $\alpha$ ), causing molecular chelation, which inhibited the DNA binding ability of HNF-4 $\alpha$ (1134-1146 bp) to HBV enhancer I, resulting in a decrease in enhancer I activity and HBV gene transcription (Wang et al., 2012, 2015).

The sex hormone signaling axis is also associated with HCV replication, E2 was found to inhibit production of mature $\mathrm{HCV}$ virions at the virion assembly/secretion phase through binding to ER- $\alpha$ (Hayashida et al., 2010) according to Magri et al. (2017) estrogen pathway inhibited hepatitis $C$ virus acting by interfering with assembly/release phases of its life cycle. In addition, one study suggested selective estrogen receptor modulators (SERMs) seemed to target multiple steps of HCV viral life cycle such as replication and post replication events, and it may be potential candidates for the treatment of HCV infection (Murakami et al., 2013). Interestingly, the HCV virus production also affects the sex hormone signal axis. Kanda et al. (2008) have demonstrated that HCV core protein can enhance AR-mediated transcriptional activity by activating JAK/STAT signaling pathway. These aforementioned studies might elucidate the role of sex hormone in modulating $\mathrm{HCV}$ infecting hepatocytes cells which may contribute to the sex bias in HCV infection.

\section{OTHER VIRUSES}

Besides coronaviruses family, TMPRSS2 function in a similar way to the de novo infection of IAV, which is also regulated by androgen/AR axis (Figure 1A). Bottcher-Friebertshauser et al. (2010) first suggested that TMPRSS2 and human airway trypsinlike protease (HAT) are candidates for proteolytic activation of influenza viruses in vivo (Bottcher-Friebertshauser et al., 2010). HA was a prerequisite for successful binding to sialic acid-containing cell surface receptors and fusion between viral and endosomal membranes during virus entry. Cleavage of HA is essential for infection and determines viral pathogenicity and tissue tropism (Sakai et al., 2016). HA is synthesized as a precursor protein, HA0, and needs to be cleaved by a host cell protease into subunits HA1 and HA2 to gain fusion capacity (Figure 1F; Bottcher-Friebertshauser et al., 2010; Sakai et al., 2016). The residues of HA comprise the N-terminal of the scissile bond $(\downarrow)$ P1 and the C-terminal P1'; corresponding residues in the substrate binding domain of the activating enzyme are designated S1 and S1' (Schechter and Berger, 1967; Luczo et al., 2015). Proteolytic cleavage of HA has been demonstrated to occur on the smooth membranes within the trans-Golgi network or at the cell surface for highly pathogenic and lowly pathogenic viruses, respectively (Bottcher-Friebertshauser et al., 2010). Unlike the membrane priming of TMPRSS2 to the S protein of SARSCoV-2, membrane-bound TMPRSS2 cleaved the HA but this did not necessarily lead to its proteolytic activation (BöttcherFriebertshäuser et al., 2014). Meanwhile, the newly synthesized HA within the cell was also cleaved by TMPRSS2, most probably during the transport of $\mathrm{HA}$ from the endoplasmic reticulum to the plasma membrane, where, virus assembly and budding take place (Figure 1G; Bottcher-Friebertshauser et al., 2010; Böttcher-Friebertshäuser et al., 2014). HAT and TMPRSS2 mediate proteolytic cleavage at a highly conserved arginine residue (Baron et al., 2013; Garten et al., 2015). Cleavage activation of TMPRSS2 was shown to occur autocatalytically. TMPRSS2 seems to possess only marginal enzymatic activity at the cell surface, whereas, HAT is a fully enzymatically active protease at the cell surface (Garten et al., 2015). These results further support the concept that TMPRSS2 cleaves the viral glycoproteins in different cellular compartments, leading to different functionality. Taken together, these findings indicate that potent protease inhibitors targeting TMPRSS2 are potential novel drugs for virus treatment.

Zika virus, a neglected mosquito-borne Flavivirus, was recently reported to establish long-term infection in the testes by preferentially infecting spermatogonia, primary spermatocytes and sertoli cells, thus resulting in sexual transmission and impaired male fertility (Lozier et al., 2018; Clancy et al., 2019). Our understanding of the mechanisms involved was recently advanced, as shown in Figure 2C. Yang et al. (2020) reported that S100A4 + macrophages may facilitate ZIKV crossing of the 
blood-testis barrier in multiple ways, establishing a biological association between male steroids and ZIKV infection.

Both the calcium binding protein S100A4/Mts1 and its endogenous receptor (receptor for advanced glycosylation end products; RAGE) have been implicated in the development of sex hormone-dependent formation of the cortical bone (Erlandsson et al., 2013) and pulmonary arterial hypertension (Dempsie et al., 2011). It was shown that physiological concentrations of E2 increased S100A4 expression led to cell proliferation, which was inhibited by soluble RAGE, by antagonizing the membrane-bound form of RAGE. Estrogen-related receptor $\gamma$ $(E R R \gamma)$ promotes the aggressiveness of endometrial cancer by activating the transcription of S100A4 (Hua et al., 2018). In feedback regulation, Ren et al. (2019) reported that the activity of the S100A4 promoter-driven Cre recombinase (S100A4Cre) is restricted to CD45 + cells of hematopoietic origin, causing sex-specific changes in the expression of genes in regulating fertility and endocrine function. Consistent with this, the CD45 + myeloid macrophage subpopulation located in mice testes, which is susceptible to ZIKV infection, comprised mainly of S100A4 + cells. Mechanically, it was demonstrated that interferon $-\gamma$ secreted by S100A $4+$ macrophages induced the tight junction protein Claudin-1 to translocate from the plasma membrane into the nuclei, thus increasing the permeability of the blood-testis barrier (an indispensable structure surrounding the seminiferous tubules and protecting the spermatogenic cells inside from viral infection and immune attack). Whether S100A4 directly functions in ZIKV infection through a sexually dimorphic mechanism remains to be determined. A few studies have also shown the various roles of S100A4 + cells in the pathogenesis of sexually transmitted viruses, which indicates that S100A4 is a promising target of viral infectious diseases.

The infection of RSV is also showed a male propensity in severe RSV bronchiolitis. Meta-analyses showed that the gender of male is a known risk factor for the disease (Lanari et al., 2015; De Jacobis et al., 2020; Orimadegun et al., 2020). A recent study showed that upon androgen treatment, higher amounts of RSV were detected in body fluids in comparison to solvent (Echchgadda et al., 2011). The current researches contribute the sex difference usually from the aspects from the immune discrepancy between genders (Carvajal et al., 2019), the possible direct mechanisms by which AR axis may crosstalk with the virus are lacking.

Finally, the outbreaks of EVD are clinically evidenced a sexual transmission. Even after 6 months to more than one year after

\section{REFERENCES}

Akula, S. M., Naranatt, P. P., Walia, N. S., Wang, F. Z., Fegley, B., and Chandran, B. (2003). Kaposi's sarcoma-associated herpesvirus (human herpesvirus 8) infection of human fibroblast cells occurs through endocytosis. J. Virol. 77, 7978-7990. doi: 10.1128/jvi.77.14.7978-7990.2003

Akuta, N., Suzuki, F., Kawamura, Y., Yatsuji, H., Sezaki, H., Suzuki, Y., et al. (2007). Predictive factors of early and sustained responses to peginterferon plus ribavirin combination therapy in Japanese patients infected with hepatitis $C$ virus genotype $1 \mathrm{~b}$ : amino acid substitutions in the core region and low-density lipoprotein cholesterol levels. J. Hepatol. 46, 403-410. doi: 10.1016/j.jhep.2006. 09.019 recovery from EVD, male patients can also transmit the EBOV to their partner (Mate et al., 2015). And the EBOV RNA can be detected from semen tissues up to 965 days, from the onset of EVD (Fischer et al., 2017). Therefore, the research into the sexual transmission mechanism of ZIKV may provide a reference for studying the disparity in related diseases caused by EBV infection.

\section{CONCLUSION}

Currently, our knowledge on the potential mechanisms determining sex disparity in infectious diseases, either immunological or via signaling pathways, is fragmented and not exhaustive. The male predominance of multiple types of human viruses has been clinically observed in viral infectious diseases; however the underlying mechanisms of male sex steroids action need further investigation, especially its versatile functions by targeting on different stages of virus lifecycle. In terms of the initial virus infection, the infection pathway is likely to influence the duration and severity of infection. Thus, in-depth studies on the function of sex hormones in each specific step of the virus life cycle will be vital. The molecular mechanisms responsible for sex bias in virus infections are only beginning to be revealed; however, identification of the key molecules and signal pathways involved may provide new insight into identifying high-risk groups and disclosing new targets for personalized medicine, targeted drugs and vaccinology.

\section{AUTHOR CONTRIBUTIONS}

JFW contributed to the conception, design, and writing of the manuscript. LZ contributed to manuscript drafting of the revised one. XW contributed to the conception, writing, and critical reviewing of the manuscript. All authors made the final approval and the agreement to account for all aspects of the manuscript.

\section{FUNDING}

This study was supported by grants from the National Natural Science Foundation of China (81873966), the Scientific Research Foundation for Advanced Talents of Fujian Medical University (XRCZX2019016), and Open Research Fund of the State Key Laboratory of Virology of China (2020KF007) to XW.

Al-Temaimi, R., Alroughani, R., Jacob, S., and Al-Mulla, F. (2015). Gender influence in EBV antibody response in multiple sclerosis patients from Kuwait. J. Neuroimmunol. 285, 57-61. doi: 10.1016/j.jneuroim.2015.05.021

Baggio, G., Corsini, A., Floreani, A., Giannini, S., and Zagonel, V. (2013). Gender medicine: a task for the third millennium. Clin. Chem. Lab. Med. 51, 713-727. doi: 10.1515/cclm-2012-0849

Bakr, I., Rekacewicz, C., El Hosseiny, M., Ismail, S., El Daly, M., El-Kafrawy, S., et al. (2006). Higher clearance of hepatitis $C$ virus infection in females compared with males. Gut 55, 1183-1187. doi: 10.1136/gut.2005.078147

Baron, J., Tarnow, C., Mayoli-Nussle, D., Schilling, E., Meyer, D., Hammami, M., et al. (2013). Matriptase, HAT, and TMPRSS2 activate the hemagglutinin of H9N2 influenza A viruses. J. Virol. 87, 1811-1820. doi: 10.1128/JVI.02320-12 
Bertram, S., Heurich, A., Lavender, H., Gierer, S., Danisch, S., Perin, P., et al. (2012). Influenza and SARS-coronavirus activating proteases TMPRSS2 and HAT are expressed at multiple sites in human respiratory and gastrointestinal tracts. PLoS One 7:e35876. doi: 10.1371/journal.pone.0035876

Bestle, D., Heindl, M. R., Limburg, H., Van Lam van, T., Pilgram, O., Moulton, H., et al. (2020). TMPRSS2 and furin are both essential for proteolytic activation of SARS-CoV-2 in human airway cells. Life Sci. Alliance 3:e202000786. doi: 10.26508/lsa.202000786

Bosch, F. X., Ribes, J., Diaz, M., and Cleries, R. (2004). Primary liver cancer: worldwide incidence and trends. Gastroenterology 127, S5-S16. doi: 10.1053/ j.gastro.2004.09.011

Bottcher-Friebertshauser, E., Freuer, C., Sielaff, F., Schmidt, S., Eickmann, M., Uhlendorff, J., et al. (2010). Cleavage of influenza virus hemagglutinin by airway proteases TMPRSS2 and HAT differs in subcellular localization and susceptibility to protease inhibitors. J. Virol. 84, 5605-5614. doi: 10.1128/JVI. 00140-10

Böttcher-Friebertshäuser, E., Garten, W., Matrosovich, M., and Klenk, H. D. (2014). The Hemagglutinin: a Determinant of Pathogenicity. Curr. Top. Microbiol. Immunol. 385, 3-34.

Bradley, H., Hall, E. W., Rosenthal, E. M., Sullivan, P. S., Ryerson, A. B., and Rosenberg, E. S. (2020). Hepatitis C Virus Prevalence in 50 U.S. States and D.C. by Sex, Birth Cohort, and Race: 2013-2016. Hepatol. Commun. 4, 355-370. doi: 10.1002/hep4.1457

Carvajal, J. J., Avellaneda, A. M., Salazar-Ardiles, C., Maya, J. E., Kalergis, A. M., and Lay, M. K. (2019). Host Components Contributing to Respiratory Syncytial Virus Pathogenesis. Front. Immunol. 10:2152. doi: 10.3389/fimmu.2019.02152

Cattrini, C., Bersanelli, M., Latocca, M. M., Conte, B., Vallome, G., and Boccardo, F. (2020). Sex Hormones and Hormone Therapy during COVID19 Pandemic: implications for Patients with Cancer. Cancers 12:2325. doi: 10. 3390/cancers 12082325

Chakraborty, S., Veettil, M. V., and Chandran, B. (2012). Kaposi's Sarcoma Associated Herpesvirus Entry into Target Cells. Front. Microbiol. 3:6. doi: 10. 3389/fmicb.2012.00006

Chandran, B. (2010). Early events in Kaposi's sarcoma-associated herpesvirus infection of target cells. J. Virol. 84, 2188-2199. doi: 10.1128/JVI.01334-09

Cheng, Z., Zhou, J., To, K. K., Chu, H., Li, C., Wang, D., et al. (2015). Identification of TMPRSS2 as a Susceptibility Gene for Severe 2009 Pandemic A(H1N1) Influenza and A(H7N9) Influenza. J. Infect. Dis. 212, 1214-1221. doi: 10.1093/ infdis/jiv246

Chiu, C. M., Yeh, S. H., Chen, P. J., Kuo, T. J., Chang, C. J., Chen, P. J., et al. (2007). Hepatitis B virus X protein enhances androgen receptor-responsive gene expression depending on androgen level. Proc. Natl. Acad. Sci. U. S. A. 104, 2571-2578. doi: 10.1073/pnas.0609498104

Claessens, F., Verrijdt, G., Schoenmakers, E., Haelens, A., Peeters, B., Verhoeven, G., et al. (2001). Selective DNA binding by the androgen receptor as a mechanism for hormone-specific gene regulation. J. Steroid Biochem. Mol. Biol. 76, 23-30. doi: 10.1016/s0960-0760(00)00154-0

Clancy, C. S., Van Wettere, A. J., Morrey, J. D., and Julander, J. G. (2019). Zika Virus Associated Pathology and Antigen Presence in the Testicle in the Absence of Sexual Transmission During Subacute to Chronic Infection in a Mouse Model. Sci. Rep. 9:8325. doi: 10.1038/s41598-019-44582-9

Counotte, M. J., Kim, C. R., Wang, J., Bernstein, K., Deal, C. D., Broutet, N. J. N., et al. (2018). Sexual transmission of Zika virus and other flaviviruses: a living systematic review. PLoS Med. 15:e1002611. doi: 10.1371/journal.pmed.1002611

Coutard, B., Valle, C., de Lamballerie, X., Canard, B., Seidah, N. G., and Decroly, E. (2020). The spike glycoprotein of the new coronavirus 2019-nCoV contains a furin-like cleavage site absent in $\mathrm{CoV}$ of the same clade. Antiviral Res 176:104742. doi: 10.1016/j.antiviral.2020.104742

Dai, C., Heemers, H., and Sharifi, N. (2017). Androgen Signaling in Prostate Cancer. Cold Spring Harb. Perspect. Med. 7:a030452. doi: 10.1101/cshperspect. a030452

De Jacobis, I. T., Vona, R., Straface, E., Gambardella, L., Ceglie, G., de Gennaro, F., et al. (2020). Sex differences in blood pro-oxidant status and platelet activation in children admitted with respiratory syncytial virus bronchiolitis: a pilot study. Ital. J. Pediatr. 46:29. doi: 10.1186/s13052-020-0792-x

Dempsie, Y., Nilsen, M., White, K., Mair, K. M., Loughlin, L., Ambartsumian, N., et al. (2011). Development of pulmonary arterial hypertension in mice over-expressing S100A4/Mts1 is specific to females. Respir. Res. 12:159. doi: 10.1186/1465-9921-12-159

Den Boon, S., Marston, B. J., Nyenswah, T. G., Jambai, A., Barry, M., Keita, S., et al. (2019). Ebola Virus Infection Associated with Transmission from Survivors. Emerg. Infect. Dis. 25, 249-255. doi: 10.3201/eid2502.181011

Duffy, M. R., Chen, T. H., Hancock, W. T., Powers, A. M., Kool, J. L., Lanciotti, R. S., et al. (2009). Zika virus outbreak on Yap Island, Federated States of Micronesia. N. Engl. J. Med. 360, 2536-2543. doi: 10.1056/NEJMoa0805715

Echchgadda, I., Chang, T. H., Sabbah, A., Bakri, I., Ikeno, Y., Hubbard, G. B., et al. (2011). Oncolytic targeting of androgen-sensitive prostate tumor by the respiratory syncytial virus (RSV): consequences of deficient interferondependent antiviral defense. BMC Cancer 11:43. doi: 10.1186/1471-2407$11-43$

El-Serag, H. B. (2012). Epidemiology of viral hepatitis and hepatocellular carcinoma. Gastroenterology 142, 1264-1273.e1. doi: 10.1053/j.gastro.2011.12. 061

Erlandsson, M. C., Bian, L., Jonsson, I. M., Andersson, K. M., and Bokarewa, M. I. (2013). Metastasin S100A4 is a mediator of sex hormone-dependent formation of the cortical bone. Mol. Endocrinol. 27, 1311-1321. doi: 10.1210/me.20121398

Esumi, M., Ishibashi, M., Yamaguchi, H., Nakajima, S., Tai, Y., Kikuta, S., et al. (2015). Transmembrane serine protease TMPRSS2 activates hepatitis C virus infection. Hepatology 61, 437-446. doi: 10.1002/hep.27426

Evans, M. J., von Hahn, T., Tscherne, D. M., Syder, A. J., Panis, M., Wolk, B., et al. (2007). Claudin-1 is a hepatitis C virus co-receptor required for a late step in entry. Nature 446, 801-805. doi: 10.1038/nature05654

Fischer, W. A., Brown, J., Wohl, D. A., Loftis, A. J., Tozay, S., Reeves, E., et al. (2017). Ebola Virus Ribonucleic Acid Detection in Semen More Than Two Years After Resolution of Acute Ebola Virus Infection. Open Forum Infect. Dis. 4:ofx155. doi: 10.1093/ofid/ofx155

FitzGerald, L. M., Agalliu, I., Johnson, K., Miller, M. A., Kwon, E. M., HurtadoColl, A., et al. (2008). Association of TMPRSS2-ERG gene fusion with clinical characteristics and outcomes: results from a population-based study of prostate cancer. BMC Cancer 8:230. doi: 10.1186/1471-2407-8-230

Garten, W., Braden, C., Arendt, A., Peitsch, C., Baron, J., Lu, Y., et al. (2015). Influenza virus activating host proteases: identification, localization and inhibitors as potential therapeutics. Eur. J. Cell Biol. 94, 375-383. doi: 10.1016/ j.ejcb.2015.05.013

Gebhard, C., Regitz-Zagrosek, V., Neuhauser, H. K., Morgan, R., and Klein, S. L. (2020). Impact of sex and gender on COVID-19 outcomes in Europe. Biol. Sex Differ. 11:29. doi: 10.1186/s13293-020-00304-9

Gemmati, D., Bramanti, B., Serino, M. L., Secchiero, P., Zauli, G., and Tisato, V. (2020). COVID-19 and Individual Genetic Susceptibility/Receptivity: role of ACE1/ACE2 Genes, Immunity, Inflammation and Coagulation. Might the Double X-chromosome in Females Be Protective against SARS-CoV-2 Compared to the Single X-Chromosome in Males? Int. J. Mol. Sci. 21:3474. doi: 10.3390/ijms21103474

Giagulli, V. A., Guastamacchia, E., Magrone, T., Jirillo, E., Lisco, G., De Pergola, G., et al. (2021). Worse progression of COVID-19 in men: is testosterone a key factor? Andrology 9, 53-64. doi: 10.1111/andr.12836

Guan, W. J., Ni, Z. Y., Hu, Y., Liang, W. H., Ou, C. Q., He, J. X., et al. (2020). Clinical Characteristics of Coronavirus Disease 2019 in China. N. Engl. J. Med. 382, 1708-1720. doi: 10.1056/NEJMoa2002032

Hackett, G., and Kirby, M. (2020). Testosterone deficiency in men infected with COVID-19. Trends Urol. Mens Health 11, 7-10. doi: 10.1002/tre.773

Haffner, M. C., Aryee, M. J., Toubaji, A., Esopi, D. M., Albadine, R., Gurel, B., et al. (2010). Androgen-induced TOP2B-mediated double-strand breaks and prostate cancer gene rearrangements. Nat. Genet. 42, 668-675. doi: 10.1038/ng. 613

Hara, S., Nagata, K., Kumata, K., Matsushita, M., Kuwamoto, S., Kato, M., et al. (2018). Estradiol Affects Epstein-Barr Virus Reactivation-Induced Thyrotropin Receptor Antibody and Immunoglobulin Production in Graves' Disease Patients and Healthy Controls. Viral. Immunol. 31, 486-491. doi: 10.1089/vim. 2018.0032

Hara, S., Nagata, K., Nakayama, Y., Higaki, K., Matsushita, M., Kuwamoto, S., et al. (2019). High Level Estradiol Induces EBV Reactivation and EBV gp350/220(+)CD138(+) Double-positive B Cell Population in Graves' Disease 
Patients and Healthy Controls. Yonago Acta Med. 62, 240-243. doi: 10.33160/ yam.2019.06.010

Hayashida, K., Shoji, I., Deng, L., Jiang, D. P., Ide, Y. H., and Hotta, H. (2010). 17beta-estradiol inhibits the production of infectious particles of hepatitis C virus. Microbiol. Immunol. 54, 684-690. doi: 10.1111/j.1348-0421.2010.00 268.x

Heurich, A., Hofmann-Winkler, H., Gierer, S., Liepold, T., Jahn, O., and Pohlmann, S. (2014). TMPRSS2 and ADAM17 cleave ACE2 differentially and only proteolysis by TMPRSS 2 augments entry driven by the severe acute respiratory syndrome coronavirus spike protein. J. Virol. 88, 1293-1307. doi: 10.1128/JVI. 02202-13

Hoffmann, M., Kleine-Weber, H., Schroeder, S., Kruger, N., Herrler, T., Erichsen, S., et al. (2020). SARS-CoV-2 Cell Entry Depends on ACE2 and TMPRSS2 and Is Blocked by a Clinically Proven Protease Inhibitor. Cell 181, 271-280.e8. doi: $10.1016 /$ j.cell.2020.02.052

Hua, T., Wang, X., Chi, S., Liu, Y., Feng, D., Zhao, Y., et al. (2018). Estrogenrelated receptor gamma promotes the migration and metastasis of endometrial cancer cells by targeting S100A4. Oncol. Rep. 40, 823-832. doi: 10.3892/or.2018.6471

Hung, C. Y., Lin, T. L., Kuo, Y. C., Hsieh, C. H., Wang, H. M., and Hsu, C. L. (2017). Progesterone analogues reduce plasma Epstein-Barr virus DNA load and improve pain control in recurrent/metastatic nasopharyngeal carcinoma patients under supportive care. Biomed. J. 40, 212-218. doi: 10.1016/j.bj.2017. 06.006

Hussain, A. N., Hussain, F., and Hashmi, S. K. (2020). Role of testosterone in COVID-19 patients - A double-edged sword? Med. Hypotheses 144:110287. doi: $10.1016 /$ j.mehy.2020.110287

Iuliano, A. D., Roguski, K. M., Chang, H. H., Muscatello, D. J., Palekar, R., Tempia, S., et al. (2018). Estimates of global seasonal influenza-associated respiratory mortality: a modelling study. Lancet 391, 1285-1300. doi: 10.1016/S01406736(17)33293-2

Iyer, J. K., Kalra, M., Kaul, A., Payton, M. E., and Kaul, R. (2017). Estrogen receptor expression in chronic hepatitis $\mathrm{C}$ and hepatocellular carcinoma pathogenesis. World J. Gastroenterol. 23, 6802-6816. doi: 10.3748/wjg.v23.i37. 6802

Jemal, A., Bray, F., Center, M. M., Ferlay, J., Ward, E., and Forman, D. (2011). Global cancer statistics. CA Cancer J. Clin. 61, 69-90. doi: 10.3322/caac.20107

Jones, B. G., Sealy, R. E., Penkert, R. R., Surman, S. L., Maul, R. W., Neale, G., et al. (2019). Complex sex-biased antibody responses: estrogen receptors bind estrogen response elements centered within immunoglobulin heavy chain gene enhancers. Int. Immunol. 31, 141-156. doi: 10.1093/intimm/dxy074

Kanda, T., Steele, R., Ray, R., and Ray, R. B. (2008). Hepatitis C virus core protein augments androgen receptor-mediated signaling. J. Virol. 82, 11066-11072. doi: 10.1128/JVI.01300-08

Kawase, M., Shirato, K., van der Hoek, L., Taguchi, F., and Matsuyama, S. (2012). Simultaneous treatment of human bronchial epithelial cells with serine and cysteine protease inhibitors prevents severe acute respiratory syndrome coronavirus entry. J. Virol. 86, 6537-6545. doi: 10.1128/JVI.00094-12

Kirchdoerfer, R. N., Cottrell, C. A., Wang, N., Pallesen, J., Yassine, H. M., Turner, H. L., et al. (2016). Pre-fusion structure of a human coronavirus spike protein. Nature 531, 118-121. doi: 10.1038/nature17200

Klein, S. L. (2012). Immune cells have sex and so should journal articles. Endocrinology 153, 2544-2550. doi: 10.1210/en.2011-2120

Kleine-Weber, H., Elzayat, M. T., Hoffmann, M., and Pohlmann, S. (2018). Functional analysis of potential cleavage sites in the MERS-coronavirus spike protein. Sci. Rep. 8:16597. doi: 10.1038/s41598-018-34859-w

Lanari, M., Prinelli, F., Adorni, F., Di Santo, S., Vandini, S., Silvestri, M., et al. (2015). Risk factors for bronchiolitis hospitalization during the first year of life in a multicenter Italian birth cohort. Ital. J. Pediatr. 41:40. doi: 10.1186/s13052015-0149-z

Langer, C., Gansz, B., Goepfert, C., Engel, T., Uehara, Y., von Dehn, G., et al. (2002). Testosterone up-regulates scavenger receptor BI and stimulates cholesterol efflux from macrophages. Biochem. Biophys. Res. Commun. 296, 1051-1057. doi: 10.1016/s0006-291x(02)02038-7

Lee, H. M., and Banini, B. A. (2019). Updates on Chronic HBV: current Challenges and Future Goals. Curr. Treat. Options Gastroenterol. 17, 271-291. doi: 10.1007/ s11938-019-00236-3

Limburg, H., Harbig, A., Bestle, D., Stein, D. A., Moulton, H. M., Jaeger, J., et al. (2019). TMPRSS2 Is the Major Activating Protease of Influenza A Virus in Primary Human Airway Cells and Influenza B Virus in Human Type II Pneumocytes. J. Virol. 93, e00649-19. doi: 10.1128/JVI.00649-19

Lin, B., Ferguson, C., White, J. T., Wang, S., Vessella, R., True, L. D., et al. (1999). Prostate-localized and androgen-regulated expression of the membrane-bound serine protease TMPRSS2. Cancer Res. 59, 4180-4184.

Lorenzo, M. E., Hodgson, A., Robinson, D. P., Kaplan, J. B., Pekosz, A., and Klein, S. L. (2011). Antibody responses and cross protection against lethal influenza A viruses differ between the sexes in C57BL/6 mice. Vaccine 29, 9246-9255. doi: 10.1016/j.vaccine.2011.09.110

Lozier, M. J., Burke, R. M., Lopez, J., Acevedo, V., Amador, M., Read, J. S., et al. (2018). Differences in Prevalence of Symptomatic Zika Virus Infection, by Age and Sex-Puerto Rico, 2016. J. Infect. Dis. 217, 1678-1689. doi: 10.1093/infdis/ jix630

Lucas, J. M., Heinlein, C., Kim, T., Hernandez, S. A., Malik, M. S., True, L. D., et al. (2014). The androgen-regulated protease TMPRSS2 activates a proteolytic cascade involving components of the tumor microenvironment and promotes prostate cancer metastasis. Cancer Discov. 4, 1310-1325. doi: 10.1158/21598290.CD-13-1010

Luczo, J. M., Stambas, J., Durr, P. A., Michalski, W. P., and Bingham, J. (2015). Molecular pathogenesis of $\mathrm{H} 5$ highly pathogenic avian influenza: the role of the haemagglutinin cleavage site motif. Rev. Med. Virol. 25, 406-430. doi: 10.1002/ rmv.1846

Magri, A., Barbaglia, M. N., Foglia, C. Z., Boccato, E., Burlone, M. E., Cole, S., et al. (2017). 17,beta-estradiol inhibits hepatitis $C$ virus mainly by interference with the release phase of its life cycle. Liver Int. 37, 669-677. doi: 10.1111/liv.13303

Majdic, G. (2020). Could Sex/Gender Differences in ACE2 Expression in the Lungs Contribute to the Large Gender Disparity in the Morbidity and Mortality of Patients Infected With the SARS-CoV-2 Virus? Front Cell Infect Microbiol 10:327. doi: $10.3389 /$ fcimb.2020.00327

Mate, S. E., Kugelman, J. R., Nyenswah, T. G., Ladner, J. T., Wiley, M. R., CordierLassalle, T., et al. (2015). Molecular Evidence of Sexual Transmission of Ebola Virus. N. Engl. J. Med. 373, 2448-2454. doi: 10.1056/NEJMoa1509773

McCoy, J., Wambier, C. G., Herrera, S., Vano-Galvan, S., Gioia, F., Comeche, B., et al. (2021). Androgen receptor genetic variant predicts COVID-19 disease severity: a prospective longitudinal study of hospitalized COVID-19 male patients. J. Eur. Acad. Dermatol. Venereol. 35, e15-e17. doi: 10.1111/jdv.16956

McKee, D. L., Sternberg, A., Stange, U., Laufer, S., and Naujokat, C. (2020). Candidate drugs against SARS-CoV-2 and COVID-19. Pharmacol. Res. 157:104859. doi: 10.1016/j.phrs.2020.104859

Megahed, F. A. K., Zhou, X., and Sun, P. (2020). The Interactions between HBV and the Innate Immunity of Hepatocytes. Viruses 12:285. doi: 10.3390/v12030285

Meng, J., Mostaghel, E. A., Vakar-Lopez, F., Montgomery, B., True, L., and Nelson, P. S. (2011). Testosterone regulates tight junction proteins and influences prostatic autoimmune responses. Horm. Cancer 2, 145-156. doi: 10.1007/ s12672-010-0063-1

Mjaess, G., Karam, A., Aoun, F., Albisinni, S., and Roumeguere, T. (2020). COVID19 and the male susceptibility: the role of ACE2, TMPRSS2 and the androgen receptor. Prog. Urol. 30, 484-487. doi: 10.1016/j.purol.2020.05.007

Montopoli, M., Zumerle, S., Vettor, R., Rugge, M., Zorzi, M., Catapano, C. V., et al. (2020). Androgen-deprivation therapies for prostate cancer and risk of infection by SARS-CoV-2: a population-based study $(\mathrm{N}=4532)$. Ann. Oncol. 31, 1040-1045. doi: 10.1016/j.annonc.2020.04.479

Moulton, V. R. (2018). Sex Hormones in Acquired Immunity and Autoimmune Disease. Front. Immunol. 9:2279. doi: 10.3389/fimmu.2018.02279

Murakami, Y., Fukasawa, M., Kaneko, Y., Suzuki, T., Wakita, T., and Fukazawa, H. (2013). Selective estrogen receptor modulators inhibit hepatitis $C$ virus infection at multiple steps of the virus life cycle. Microbes Infect. 15, 45-55. doi: 10.1016/j.micinf.2012.10.003

Musso, D., Nilles, E. J., and Cao-Lormeau, V. M. (2014). Rapid spread of emerging Zika virus in the Pacific area. Clin. Microbiol. Infect. 20, O595-O596. doi: 10.1111/1469-0691.12707

Orimadegun, A. E., Adepoju, A. A., and Myer, L. (2020). A Systematic Review and Meta-analysis of Sex Differences in Morbidity and Mortality of Acute Lower Respiratory Tract Infections Among African Children. J. Pediatr. Rev. 8, 65-78. doi: 10.32598/jpr.8.2.65

Ortona, E., Pierdominici, M., and Rider, V. (2019). Editorial: sex Hormones and Gender Differences in Immune Responses. Front. Immunol. 10:1076. doi: 10. 3389/fimmu.2019.01076 
Park, K., Dalton, J. T., Narayanan, R., Barbieri, C. E., Hancock, M. L., Bostwick, D. G., et al. (2014). TMPRSS2:ERG gene fusion predicts subsequent detection of prostate cancer in patients with high-grade prostatic intraepithelial neoplasia. J. Clin. Oncol. 32, 206-211. doi: 10.1200/JCO.2013.49.8386

Perner, S., Mosquera, J. M., Demichelis, F., Hofer, M. D., Paris, P. L., Simko, J., et al. (2007). TMPRSS2-ERG Fusion Prostate Cancer: an Early Molecular Event Associated with Invasion. Am. J. Surg. Pathol. 31, 882-888. doi: 10.1097/01.pas. 0000213424.38503.aa

Qiao, Y., Wang, X. M., Mannan, R., Pitchiaya, S., Zhang, Y., Wotring, J. W., et al. (2020). Targeting transcriptional regulation of SARS-CoV-2 entry factors ACE2 and TMPRSS2. Proc. Natl. Acad. Sci. U. S. A. 118:e2021450118. doi: 10.1073/ pnas. 2021450118

Raghu, H., Sharma-Walia, N., Veettil, M. V., Sadagopan, S., and Chandran, B. (2009). Kaposi's sarcoma-associated herpesvirus utilizes an actin polymerization-dependent macropinocytic pathway to enter human dermal microvascular endothelial and human umbilical vein endothelial cells. J. Virol. 83, 4895-4911. doi: 10.1128/JVI.02498-08

Ragia, G., and Manolopoulos, V. G. (2020). Assessing COVID-19 susceptibility through analysis of the genetic and epigenetic diversity of ACE2-mediated SARS-CoV-2 entry. Pharmacogenomics 21, 1311-1329. doi: 10.2217/pgs-20200092

Reinke, L. M., Spiegel, M., Plegge, T., Hartleib, A., Nehlmeier, I., Gierer, S., et al. (2017). Different residues in the SARS-CoV spike protein determine cleavage and activation by the host cell protease TMPRSS2. PLoS One 12:e0179177. doi: 10.1371/journal.pone.0179177

Ren, Y. A., Monkkonen, T., Lewis, M. T., Bernard, D. J., Christian, H. C., Jorgez, C. J., et al. (2019). S100a4-Cre-mediated deletion of Patched1 causes hypogonadotropic hypogonadism: role of pituitary hematopoietic cells in endocrine regulation. JCI Insight 5:e126325. doi: 10.1172/jci.insight.126325

Rozenberg, S., Vandromme, J., and Martin, C. (2020). Are we equal in adversity? Does Covid-19 affect women and men differently? Maturitas 138, 62-68. doi: 10.1016/j.maturitas.2020.05.009

Ruggieri, A., Anticoli, S., D'Ambrosio, A., Giordani, L., and Viora, M. (2016). The influence of sex and gender on immunity, infection and vaccination. Ann. Ist. Super. Sanita 52, 198-204. doi: 10.4415/ANN_16_02_11

Ruggieri, A., Gagliardi, M. C., and Anticoli, S. (2018). Sex-Dependent Outcome of Hepatitis B and C Viruses Infections: synergy of Sex Hormones and Immune Responses? Front. Immunol. 9:2302. doi: 10.3389/fimmu.2018.02302

Sakai, K., Ami, Y., Nakajima, N., Nakajima, K., Kitazawa, M., Anraku, M., et al. (2016). TMPRSS2 Independency for Haemagglutinin Cleavage In Vivo Differentiates Influenza B Virus from Influenza A Virus. Sci. Rep. 6:29430. doi: $10.1038 /$ srep29430

Sasaki, Y., Ishii, T., Maeda, T., Mori, T., Shigeta, T., Kashiwagi, K., et al. (2020). Sex difference in clinical presentation of patients with infectious mononucleosis caused by Epstein-Barr virus. J. Infect. Chemother. 26, 1181-1185. doi: 10.1016/ j.jiac.2020.06.009

Scarselli, E., Ansuini, H., Cerino, R., Roccasecca, R. M., Acali, S., Filocamo, G., et al. (2002). The human scavenger receptor class B type I is a novel candidate receptor for the hepatitis C virus. EMBO J. 21, 5017-5025. doi: 10.1093/emboj/ cdf529

Schechter, I., and Berger, A. (1967). On the size of the active site in proteases. I. Papain. Biochem. Biophys. Res. Commun. 27, 157-162. doi: 10.1016/s0006$291 \mathrm{x}(67) 80055-\mathrm{x}$

Scully, E. P., Haverfield, J., Ursin, R. L., Tannenbaum, C., and Klein, S. L. (2020). Considering how biological sex impacts immune responses and COVID-19 outcomes. Nat. Rev. Immunol. 20, 442-447. doi: 10.1038/s41577-020-0348-8

Shen, L. W., Mao, H. J., Wu, Y. L., Tanaka, Y., and Zhang, W. (2017). TMPRSS2: a potential target for treatment of influenza virus and coronavirus infections. Biochimie 142,1-10. doi: 10.1016/j.biochi.2017.07.016

Shirato, K., Kawase, M., and Matsuyama, S. (2013). Middle East respiratory syndrome coronavirus infection mediated by the transmembrane serine protease TMPRSS2. J. Virol. 87, 12552-12561. doi: 10.1128/JVI.01890-13

Simon, F. R., Fortune, J., Iwahashi, M., Qadri, I., and Sutherland, E. (2004). Multihormonal regulation of hepatic sinusoidal Ntcp gene expression. Am. J. Physiol. Gastrointest. Liver Physiol. 287, G782-G794. doi: 10.1152/ajpgi.00379. 2003

Smith, D. F., and Toft, D. O. (2008). Minireview: the intersection of steroid receptors with molecular chaperones: observations and questions. Mol. Endocrinol. 22, 2229-2240. doi: 10.1210/me.2008-0089
Stangl, H., Graf, G. A., Yu, L., Cao, G., and Wyne, K. (2002). Effect of estrogen on scavenger receptor BI expression in the rat. J. Endocrinol. 175, 663-672. doi: $10.1677 /$ joe. 0.1750663

Stopsack, K. H., Mucci, L. A., Antonarakis, E. S., Nelson, P. S., and Kantoff, P. W. (2020). TMPRSS2 and COVID-19: serendipity or Opportunity for Intervention? Cancer Discov. 10, 779-782. doi: 10.1158/2159-8290.CD-200451

Tarnow, C., Engels, G., Arendt, A., Schwalm, F., Sediri, H., Preuss, A., et al. (2014). TMPRSS2 is a host factor that is essential for pneumotropism and pathogenicity of H7N9 influenza A virus in mice. J. Virol. 88, 4744-4751. doi: 10.1128/JVI. 03799- 13

Tsay, P. K., Tai, D. I., Chen, Y. M., Yu, C. P., Wan, S. Y., Shen, Y. J., et al. (2009). Impact of gender, viral transmission and aging in the prevalence of hepatitis B surface antigen. Chang Gung Med. J. 32, 155-164.

Ulitzky, L., Lafer, M. M., KuKuruga, M. A., Silberstein, E., Cehan, N., and Taylor, D. R. (2016). A New Signaling Pathway for HCV Inhibition by Estrogen: GPR30 Activation Leads to Cleavage of Occludin by MMP-9. PLoS One 11:e0145212. doi: 10.1371/journal.pone.0145212

Vishvkarma, R., and Rajender, S. (2020). Could SARS-CoV-2 affect male fertility? Andrologia 52:e13712. doi: 10.1111/and.13712

Walls, A. C., Park, Y. J., Tortorici, M. A., Wall, A., McGuire, A. T., and Veesler, D. (2020). Structure, Function, and Antigenicity of the SARSCoV-2 Spike Glycoprotein. Cell 181, 281-292.e6 doi: 10.1016/j.cell.2020.02. 058

Wang, C. C., Krantz, E., Klarquist, J., Krows, M., McBride, L., Scott, E. P., et al. (2007). Acute hepatitis C in a contemporary US cohort: modes of acquisition and factors influencing viral clearance. J. Infect. Dis. 196, 1474-1482. doi: 10. $1086 / 522608$

Wang, S. H., Chen, P. J., and Yeh, S. H. (2015). Gender disparity in chronic hepatitis B: mechanisms of sex hormones. J. Gastroenterol. Hepatol. 30, 1237-1245. doi: $10.1111 /$ jgh. 12934

Wang, S. H., Yeh, S. H., Lin, W. H., Wang, H. Y., Chen, D. S., and Chen, P. J. (2009). Identification of androgen response elements in the enhancer I of hepatitis B virus: a mechanism for sex disparity in chronic hepatitis B. Hepatology 50 , 1392-1402. doi: 10.1002/hep.23163

Wang, S. H., Yeh, S. H., Lin, W. H., Yeh, K. H., Yuan, Q., Xia, N. S., et al. (2012). Estrogen receptor alpha represses transcription of HBV genes via interaction with hepatocyte nuclear factor 4alpha. Gastroenterology 142, 989-998.e4. doi: 10.1053/j.gastro.2011.12.045

Wang, X., Zou, Z., Deng, Z., Liang, D., Zhou, X., Sun, R., et al. (2017). Male hormones activate EphA2 to facilitate Kaposi's sarcoma-associated herpesvirus infection: implications for gender disparity in Kaposi's sarcoma. PLoS Pathog. 13:e1006580. doi: 10.1371/journal.ppat.1006580

WHO (2016). WHO: Ebola Situation Report 2 March 2016 [Online]. Available Online at: https://apps.who.int/iris/handle/10665/204521 (accessed September 15, 2021).

Wong, K. C., Luscombe, G. M., and Hawke, C. (2019). Influenza infections in Australia 2009-2015: is there a combined effect of age and sex on susceptibility to virus subtypes? BMC Infect. Dis. 19:42. doi: 10.1186/s12879-019-36 $81-4$

Yamamoto, M., Matsuyama, S., Li, X., Takeda, M., Kawaguchi, Y., Inoue, J. I., et al. (2016). Identification of Nafamostat as a Potent Inhibitor of Middle East Respiratory Syndrome Coronavirus S Protein-Mediated Membrane Fusion Using the Split-Protein-Based Cell-Cell Fusion Assay. Antimicrob. Agents Chemother. 60, 6532-6539. doi: 10.1128/AAC.01043-16

Yan, H., Zhong, G., Xu, G., He, W., Jing, Z., Gao, Z., et al. (2012). Sodium taurocholate cotransporting polypeptide is a functional receptor for human hepatitis B and D virus. eLife 1:e00049. doi: 10.7554/eLife.00049

Yang, J. D., Hainaut, P., Gores, G. J., Amadou, A., Plymoth, A., and Roberts, L. R. (2019). A global view of hepatocellular carcinoma: trends, risk, prevention and management. Nat. Rev. Gastroenterol. Hepatol. 16, 589-604. doi: 10.1038/ s41575-019-0186-y

Yang, W., Wu, Y. H., Liu, S. Q., Sheng, Z. Y., Zhen, Z. D., Gao, R. Q., et al. (2020). S100A4+ macrophages facilitate zika virus invasion and persistence in the seminiferous tubules via interferon-gamma mediation. PLoS Pathog. 16:e1009019. doi: 10.1371/journal.ppat.1009019

Yang, W. J., Chang, C. J., Yeh, S. H., Lin, W. H., Wang, S. H., Tsai, T. F., et al. (2009). Hepatitis B virus $\mathrm{X}$ protein enhances the transcriptional activity of the androgen 
receptor through c-Src and glycogen synthase kinase-3beta kinase pathways. Hepatology 49, 1515-1524. doi: 10.1002/hep.22833

Zhang, H., Li, Y., Wang, H. B., Zhang, A., Chen, M. L., Fang, Z. X., et al. (2018). Ephrin receptor A2 is an epithelial cell receptor for Epstein-Barr virus entry. Nat. Microbiol. 3, 1-8. doi: 10.1038/s41564-017-0080-8

Zhou, Y., Vedantham, P., Lu, K., Agudelo, J., Carrion, R. Jr., Nunneley, J. W., et al. (2015). Protease inhibitors targeting coronavirus and filovirus entry. Antiviral Res. 116, 76-84. doi: 10.1016/j.antiviral.2015.01.011

Zhu, R., Zhang, J. S., Zhu, Y. Z., Fan, J., Mao, Y., Chen, Q., et al. (2011). HBxinduced androgen receptor expression in $\mathrm{HBV}$-associated hepatocarcinoma is independent of the methylation status of its promoter. Histol. Histopathol. 26, 23-35. doi: 10.14670/HH-26.23

Zmora, P., Moldenhauer, A. S., Hofmann-Winkler, H., and Pohlmann, S. (2015). TMPRSS2 Isoform 1 Activates Respiratory Viruses and Is Expressed in Viral Target Cells. PLoS One 10:e0138380. doi: 10.1371/journal.pone.013 8380
Conflict of Interest: The authors declare that the research was conducted in the absence of any commercial or financial relationships that could be construed as a potential conflict of interest.

Publisher's Note: All claims expressed in this article are solely those of the authors and do not necessarily represent those of their affiliated organizations, or those of the publisher, the editors and the reviewers. Any product that may be evaluated in this article, or claim that may be made by its manufacturer, is not guaranteed or endorsed by the publisher.

Copyright $\odot 2021 \mathrm{Wu}$, Zhang and Wang. This is an open-access article distributed under the terms of the Creative Commons Attribution License (CC BY). The use, distribution or reproduction in other forums is permitted, provided the original author(s) and the copyright owner(s) are credited and that the original publication in this journal is cited, in accordance with accepted academic practice. No use, distribution or reproduction is permitted which does not comply with these terms. 